\title{
REVIEWS
}

\section{Cholesterol gallstones: from epidemiology to prevention}

\author{
M Acalovschi
}

Gallstones are a major public health problem in all developed countries. Many epidemiological studies have been performed with the aim of establishing gallstone prevalence and incidence rates, and of defining risk factors, amenable to prevention. Cholesterol gallstones constitute more than $80 \%$ of stones in the Western world.

\section{Epidemiology}

The data usually employed in assessing gallstone prevalence were derived until recently from selected series of patients (necropsies, surgery, etc), which may not represent the general population. Suffice to say that the reported $0 \%$ prevalence of gallstones in the Masai population was deduced from surgical experience in that area, which is far from being an ideal way to collect epidemiological data.

Necropsy studies are subject to selection bias, which can be reduced by adjusting the data by standardisation. Necropsy studies have shown that, even after standardisation for age and sex, there are major differences between different countries (table 1). The available necropsy data, scrutinising longer intervals of time, decades ${ }^{12}$ or even a century, ${ }^{3}$ have revealed a trend of increasing gallstone prevalence.

Cholecystectomy rates, which fluctuate considerably (as much as fivefold) between countries and periods of time, have little relation to the prevalence rates. Oral cholecystography has been used by several researchers to assess gallstone prevalence, but no satisfactory evaluation on the prevalence of silent gallstones in the population was achieved.

Table 1 Age standardised necropsy prevalence of gallstones (see p 228 for list of references)

\begin{tabular}{lll}
\hline & \multicolumn{2}{l}{$\begin{array}{l}\text { Gallstone } \\
(\%)\end{array}$} \\
\cline { 2 - 3 } Country (reference) & Femalence & Males \\
\hline Chile (Marinovic et al, 1972) & 42.0 & 16.7 \\
Germany (Balzer et al, 1986) & 33.7 & 13.1 \\
Czechoslovakia (Zahor et al, 1975) & 23.3 & 13.2 \\
Sweden (Lindström, 1977) & 22.4 & 9.1 \\
Scotland (Bateson and Bouchier, 1975) & 21.7 & 9.9 \\
England (Barker et al, 1979) & 20.5 & 12.2 \\
Mexico (Mendez-Sanchez et al, 1993) & 16.2 & 5.6 \\
Finland (Domellöf et al, 1984) & 15.9 & 8.7 \\
New Zealand (Douss and Castleden, 1973) & 14.2 & 9.0 \\
USA (Lieber, 1952) & 14.1 & 5.2 \\
Australia (Cleland, 1953) & 13.0 & 6.0 \\
Japan (Newman and Northup, 1959) & 13.0 & 5.3 \\
Ireland (Hogan et al, 1977) & 12.4 & 3.4 \\
Norway (Torvik and Hoivik, 1960) & 10.4 & 5.3 \\
Romania (Acalovschi et al, 1987) & 8.4 & 5.0 \\
Greece (Kalos et al, 1977) & 6.8 & 3.5 \\
Singapore (Swang, 1970) & 6.6 & 4.3 \\
Thailand (Stitnimankarn, 1960) & 4.2 & 2.3 \\
\hline
\end{tabular}

Currently, most studies have used real time ultrasonography as a screening method in randomly selected populations. Ultrasonography does not only allow the assessment of prevalence, but it is also suitable for follow up in order to establish gallstone incidence and to define risk factors for gallstone disease.

Accurate data for local gallstone prevalence and incidence rates are not yet available for every country. The largest number of sonographic studies have been performed in Western Europe (table 2). The median prevalence rate ranges from $5.9 \%$ to $21.9 \%$, with the highest rates seen in Bergen, Norway and Schwedt, Germany and the lowest in Chianciano and Sirmione, Italy. ${ }^{4}$ The gallstone incidence evaluated in 10-11 year follow ups in Europe ranges between 0.63 and $0.93 / 100$ persons/year. $^{56}$

The highest prevalence of gallstones was found in Pima Indians from Arizona, USA by oral cholecystography screenings. ${ }^{7}$ Almost all ultrasound surveys in the Americas were conducted on Latin American populations. The prevalence rates in Hispanics were higher than those reported in European populations. A large ultrasound survey just completed (NHANES III) indicated an age standardised prevalence of gallstones higher in Mexican Americans than in non-Hispanic whites, with the lowest prevalence in non-Hispanic blacks. ${ }^{8}$ In South America, a very high gallstone prevalence was found in Chile. In Chilean women, gallstone incidence was $1.2 / 100$ women/year. ${ }^{9}$ The lowest gallstone prevalence rates were found in Asian and African countries.

In almost all populations in which the necessary data were provided, gallstones were more frequent in women than in men and the majority of persons with gallstone disease had not had a cholecystectomy and were unaware of having gallstones.

\section{Pathogenesis}

Gallstone pathogenesis must be briefly considered to facilitate the presentation of risk factors. Cholesterol gallstones, composed predominantly of cholesterol crystals, result from abnormalities in cholesterol metabolism.

Three types of abnormalities have been considered to be responsible for cholesterol gallstone formation. The first and essential requirement is bile supersaturation in cholesterol. The per cent saturation of the cholesterol in bile is determined by the molar ratio of the three major biliary lipids: cholesterol, bile acids, and phospholipids. Cholesterol super- 
Table 2 Prevalence of gallstones in the largest sonographic surveys, which included persons from all age groups (see $p 228$ for list of references)

\begin{tabular}{|c|c|c|c|c|c|}
\hline \multirow[b]{2}{*}{ City (country) } & \multirow[b]{2}{*}{ Reference } & \multirow{2}{*}{$\begin{array}{l}\text { No of } \\
\text { participants }\end{array}$} & \multicolumn{3}{|c|}{ Prevalence (\%) } \\
\hline & & & Male & Female & Global \\
\hline \multicolumn{6}{|l|}{ Europe } \\
\hline Sirmione, Italy & Barbara et al, 1987 & 1911 & 6.7 & 14.4 & 10.9 \\
\hline Copenhagen, Denmark & Jörgensen, 1987 & 3608 & 5.6 & 11.0 & 8.8 \\
\hline Bergen, Norway & Glambek et al, 1987 & 1371 & 20.3 & 23.3 & 21.9 \\
\hline Schwedt, East Germany & Berndt et al, 1989 & 3226 & 13.1 & 24.5 & 19.7 \\
\hline Timisoara, Romania & Sporea et al, 1993 & 1323 & 6.1 & 12.8 & 10.9 \\
\hline Chianciano, Italy & Loria et al, 1994 & 1804 & 3.7 & 8.4 & 5.9 \\
\hline Castellana, Italy & Misciagna et al, 1994 & 2461 & 6.4 & 12.8 & 9.2 \\
\hline Stockholm, Sweden & Muhrbeck and Ahlberg, 1995 & 556 & 11 & 18 & 15 \\
\hline 10 regions, Italy & Attili et al, 1995 & 29739 & 9.5 & 18.9 & 13.8 \\
\hline Bristol, England & Heaton et al, 1991 & 1896 & 6.8 & 8.0 & 7.5 \\
\hline Poland & Tomecki et al, 1995 & 10133 & 8.2 & 18.0 & \\
\hline Montegrotto, Italy & Okolicsany et al, 1995 & 2530 & 6.2 & 14.7 & 10.5 \\
\hline Vidauban, France & Caroli-Bosc et al, 1996 & 831 & 12.5 & 17.8 & 15.7 \\
\hline Guadalajara, Spain & Martinez de Pancorbo et al, 1997 & 536 & 7.8 & 11.5 & 9.7 \\
\hline Ulm, Germany & Kratzer et al, 1998 & 1116 & 5.8 & 6.3 & \\
\hline \multicolumn{6}{|l|}{ Asia } \\
\hline Okinawa, Japan & Nomura et al, 1988 & 2584 & 2.4 & 4.0 & 3.2 \\
\hline Srinagar, Kashmir, India & Khuroo et al, 1989 & 1104 & 3.1 & 9.6 & 6.1 \\
\hline Chiayi, Taiwan & Lu et al, 1990 & 923 & 4.5 & 4.6 & 4.6 \\
\hline Jiaotong, China & Zhao et al, 1990 & 15856 & 2.3 & 4.7 & 3.6 \\
\hline Chiang Mai, Thailand & Prathnadi et al, 1992 & 6146 & 2.5 & 3.7 & 3.1 \\
\hline Taiwan & Chen et al, 1998 & 3647 & 10.7 & 11.5 & 10.7 \\
\hline \multicolumn{6}{|l|}{ North America } \\
\hline US Hispanics & Maurer et al, 1990 & 2320 & 5.4 & 19.1 & 13.3 \\
\hline Starr County, Texas, US & Hanis et al, 1993 & 1004 & 8.0 & 20.2 & 17.9 \\
\hline NHANES III, US & Everhart et al, 1999 & 14000 & & & 14.3 \\
\hline Mexican Americans & & & 8.9 & 26.7 & \\
\hline Non-Hispanic whites & & & 8.6 & 16.6 & \\
\hline Non-Hispanic blacks & & & 5.3 & 13.9 & \\
\hline \multicolumn{6}{|l|}{ South America } \\
\hline Santiago, Chile & Covarrubias et al, 1995 & 1811 & 14.5 & 37.4 & 28.5 \\
\hline Pampas de San Juan, Peru & Moro et al, 2000 & 1534 & 16.1 & 10.7 & 14.3 \\
\hline \multicolumn{6}{|c|}{ Africa } \\
\hline Khartoum, Sudan & Bagi Abdel et al, 1991 & 252 & 5.6 & 5.1 & 5.2 \\
\hline
\end{tabular}

saturation, the essential requirement for cholesterol gallstone formation, might occur via excessive cholesterol biosynthesis (increased 3-hydroxy-3-methylglutaryl (HMG) coenzyme A (CoA) reductase activity), which is the main lithogenic mechanism (that is, in obese persons) (fig 1). A reduced acyl-CoA cholesterol acyltransferase (ACAT) activity, inhibiting cholesterol esterification, leads to an increased excretion of free cholesterol into the bile. In the non-obese, excessive cholesterol secretion could result from defective conversion of cholesterol to bile acids, due to a low or relatively low activity of cholesterol $7 \alpha$ hydroxylase, the rate limiting enzyme for bile acid biosynthesis (and cholesterol elimination). Finally, interruption of the enterohepatic circulation of bile

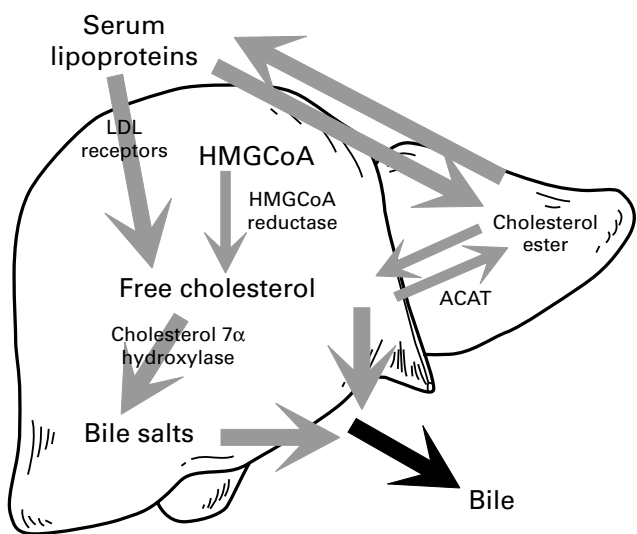

Figure 1 Metabolic pathways in cholesterol and bile acid homoeostasis $(A C A T=$ acyl-CoA cholesterol acyltransferase, $H M G C o A=3-h y d r o x y-3-m e t h y l g l u t a r y l$ coenzyme $A, L D L=$ low density lipoprotein).
Box 1: Pathogenetic mechanisms of cholesterol gallstone formation

- Supersaturation of bile in cholesterol.

- Enhanced nucleation of cholesterol crystals.

- Impaired gallbladder emptying with stasis.

- Intestinal hypomotility.

acids could increase bile saturation. Temporary interruption of the enterohepatic bile acid circulation during overnight fasting leads to a higher cholesterol/phospholipid ratio in the vesicles secreted by the liver.

The second abnormality is enhanced nucleation of cholesterol crystals. Mucin and its congeners, the major proteins, act as matrix molecules to hold cholesterol crystal aggregates together to form a stone.

There also must be sufficient time for nucleation to occur, for crystals to form and grow to microliths, and for microliths to aggregate to form gallstones, hence gallbladder stasis is a contributing factor to gallstone formation. During overnight fasting, the gallbladder does not empty so that hours of storage occur in all individuals.

It should be the sum of these three factors that determines when gallstones form. If bile is highly supersaturated, hypernucleation and stasis might be modest. Conversely, if bile were only slightly supersaturated, hypernucleation or prolonged stasis might result in gallstone formation.

Intestinal hypomotility has been recently recognised as a fourth primary factor in cholesterol lithogenesis (box 1). Having a longer exposure to intestinal micro-organisms, primary bile salts are in greater proportion deconjugated and dehydroxylated to more hydrophobic secondary bile salts. An increased proportion of the secondary bile acid deoxycholate, a potent down regulator of the rate limiting enzyme for bile acid biosynthesis, enhances cholesterol hypersecretion into bile.

\section{Risk factors}

Gallstone formation is multifactorial, both constitutional (unmodifiable) (box 2) and environmental (modifiable) (box 3) risk factors competing to lithogenesis.

Associations between the risk of gallstones and demographic characteristics have been sought from epidemiological studies. Most of these studies have looked for differences between people with gallstones and people who are stone-free (case-control studies). Unmodifiable risk factors such as age and gender have been first established, and then controlled in the search for other factors. Usually, this is

Box 2: Unmodifiable risk factors for cholesterol gallstones

- Female gender.

- Increasing age.

- Genetic factors: ethnicity, family. 
Box 3: Modifiable (environmental) risk factors for cholesterol gallstones

- Obesity.

- Rapid weight loss.

- Hypertriglyceridaemia.

- Drugs lowering serum cholesterol.

- Slow intestinal transit.

- Gallbladder stasis.

- High calorie diet.

- Highly absorbable sugars.

- Low fibre diet.

- Low calcium low vitamin $\mathrm{C}$ diet.

- Alcohol abstinence.

- Smoking.

- Sedentary behaviour.

done by multiple regression analysis. The casecontrol approach can be used to look for differences in lifestyle, such as eating and drinking habits, etc. But most of the published case-control studies suffer from inadequate sample size or various types of selection bias which confound the results. Small studies might yield false negative results (that is, fail to reveal a genuine difference). Selection bias might also create non-existing differences (false positive results). The most reliable data come from studies of asymptomatic cases identified by population screening, and those have increased in number in the last decade.

GENDER, PARITY, AND ORAL CONTRACEPTIVES In all populations of the world, regardless of overall gallstone prevalence, women are almost twice as likely as men to experience cholelithiasis. Gender is one of the most powerful influences on gallstones, which are more common in females during their fertile years as in males. This preponderance persists to a lesser extent into the postmenopausal period, but the sex difference narrows with increasing age. Among persons younger than 40 , the female/male prevalence ratio varies from 1.2 in Bergen, Norway, to 9.9 among Pima Indians. For ages 60 and older, the female/male ratio varies from 0.96 in Okinawa, Japan, to 2.9 among Mexican Americans in the south western USA.${ }^{10}$ Women with gallstones are more likely to have had a cholecystectomy than men with gallstones.

The influence of the female sex hormones has been studied in normal females, during pregnancy, and in women using oral contraceptives. The risk of gallstones is greater in younger women, and is influenced by parity. A critical review of the literature indicates that parity is associated with gallstones only in younger females. ${ }^{411}$ This risk seems to apply to both the number and age of pregnancies. For example, a woman who has four pregnancies before the age of 25 has a fourfold to 12 -fold increased risk of cholesterol gallstones compared with an age matched, weight matched nulliparous woman. ${ }^{11}$ Pregnancy favours gallstone formation through the hormonal influences on bile composition (increased biliary cholesterol secretion, decreased and unbalanced bile acid pool). Oestrogens induce an increased input to the hepatic free cholesterol pool by up-regulating the low density lipoprotein receptor. Decreased gallbladder motility during the third trimester of pregnancy and an altered function of gallbladder mucosa may favour nucleation and growth of stones. The occurrence of sludge increases steadily during pregnancy $(30 \%-35 \%)$, but gallstones develop at a lesser frequency $(2 \%-3 \%)$. Biliary sludge and most gallstones will disappear spontaneously within a few weeks after delivery. ${ }^{12}$

Several studies have confirmed an association between gallstones and use of exogenous oestrogens, whether as oral contraceptives, postmenopausal oestrogen replacement, or oestrogen administration in men. The current evidence indicates that the modern contraceptives, containing a medium/low (less than 50 $\mu \mathrm{g})$ daily dose of oestrogen, do not increase the risk of forming gallstones, but may accelerate the performance of cholecystectomy. ${ }^{13}$ Sex steroids given by other routes, such as transdermal or vaginal, are less lithogenic, ${ }^{14}$ probably by avoiding the first pass effect in the liver.

AGE

Gallstones are generally uncommon in infants and children. The recently reported increasing number of cholecystectomies in this population refers mainly to girls aged over 16 years, obese, parous, and/or of Mexican-American origin. ${ }^{15}$

All epidemiological studies showed that increasing age was associated with an increased prevalence of gallstones. Gallstones are four to 10 times more frequent in older than younger subjects. Biliary cholesterol saturation increases with age, due to a decline in the activity of cholesterol $7 \alpha$ hydroxylase, the rate limiting enzyme for bile acid synthesis. ${ }^{16}$ In the elderly, bile acid synthesis is reduced, biliary cholesterol output is increased and cholesterol saturation of bile increases, and that is true both in men and women. ${ }^{17}$ Deoxycholic acid proportion in bile increases with age through enhanced $7 \alpha$ dehydroxylation of the primary bile acids by the intestinal bacteria. In addition, increasing age allows the cumulative lithogenic action of more risk factors.

\section{GENETIC FACTORS}

Both necropsy and population studies have clearly shown the existence of racial differences that can not completely be explained by environmental factors. Cholesterol gallstone prevalence varies widely, from extremely low $(<5 \%)$ in Asian and African populations, to intermediate $(10 \%-30 \%)$ in European and Northern American populations, and to extremely high $(30 \%-70 \%)$ in populations of Native American ancestry (Pima Indians in Arizona, Mapuche Indians in Chile).

The Pima tribe of Arizona has the highest gallstone prevalence in the world: more than $70 \%$ of Pima women older than 25 had gallstones or a history of cholecystectomy. High rates of gallstone prevalence have been also reported in other North American Indian tribes, including the Chippewas, Navajo, Micmacs, and Cree-Ojibwas. A high mortality from gallbladder cancer, a disease intimately linked 
to gallstones, was found in Native Americans living in Alaska, Minnesota, Oklahoma, New Mexico, and Bolivia. That these high prevalence rates are observed in native people throughout North and South America, who differ markedly in local environment, culture, and diet argues for a common, genetically determined predisposition to gallstone formation.

Certain Hispanic populations in the USA are above average risk for gallbladder disease. Some studies strongly support the existence of Amerindian lithogenic genes in MexicanAmericans. ${ }^{18}$ The NHANES III survey confirms the higher prevalence of gallstones among Mexican-American than non-Hispanic whites. ${ }^{8}$ As not all Hispanic populations living in the USA have a high prevalence of gallstones, and gallstone prevalence in Spain is similar to that in other European countries (table 2), the hypothesis to explain these findings is the concept of genetic admixture. Miquel et al examined the role genetic admixture plays in explaining variations in gallstone disease prevalence among ethnic subpopulations in Chile, a country with a very high prevalence of gallstones and among the highest mortality rates from gallbladder cancer in the world. ${ }^{19}$ Gallstone prevalence was significantly higher in the subpopulations (Mapuches, followed by Hispanic Mestizos) with high heritage of Amerindian admixture, estimated by mtDNA analysis.

The NHANES III survey also confirmed the low gallstone prevalence among American blacks compared with whites, mentioned by several epidemiological surveys. An ultrasound survey of South African black women older than 55 has shown a $10 \%$ prevalence of stones, ${ }^{20}$ lower than in South African white women.

Genetic influence in gallstone formation is also suggested by familial clustering within populations. An increased frequency of gallstones was found among the relatives of gallstone patients as compared with families of controls. $^{21-23}$ Familial dietary habits are not likely to offer an explanation of the increased familial incidence of gallstones, in view of the negative findings in spouses. ${ }^{23}{ }^{24}$ Patients who are young when gallstones develop are more likely to have affected relatives, because an early age onset of gallstone disease would reflect a greater polygenic predisposition. The finding that gallstones are more frequent in monozygotic than in dizygotic twins strongly supported the genetic contribution to gallstone formation. A higher saturation in cholesterol of the bile and a higher correlation of the cholic and deoxycholic acid contents were found in the monozygotic as compared with dizygotic twins. ${ }^{25}$

Using inbred strains of mice, two genes have been identified that confer susceptibility to gallstones in an autosomal dominant pattern: Lith1 (the bile salt export pump, Bsep), and Lith2 (the canalicular multiorganic anion transporter, cMoat). Mice with overexpression of Lith1 gene appear unable to down-regulate the activity of HMGCoA reductase, and thus, cholesterol synthesis when fed a lithogenic diet. ${ }^{26}$ The activity of cholesterol $7 \alpha$ hydroxylase and sterol 27 hydroxylase is also downregulated. Up-regulation of cMoat induces cholesterol lithogenicity from bile salt-lecithin decoupling due to bile salt-anion binding. No human homologue of this gene has yet been found.

A genetic factor in humans, polymorphism of the apolipoprotein $\mathrm{E}$ locus, has recently been identified. Apolipoprotein E plays a part in dietary lipid absorption, transport, and distribution to the liver and peripheral tissues and exists as three different alleles: apoE2, apoE3, and apoE4. ApoE4 genotype is associated with biliary cholesterol supersaturation, rapid nucleation, an increased cholesterol content of gallstones, a rapid clearance of gallstones by lithotripsy and a high risk of recurrence after treatments that leave the gallbladder in situ. ${ }^{27}$ This allele might affect hepatocyte uptake and biliary secretion of lipids, or might act as a pronucleator in the bile.

OBESITY AND BODY FAT DISTRIBUTION

Ultrasonographic and cohort studies in selected populations have confirmed the clinical impression that gallstones are more frequent among obese than non-obese persons. Obesity is an important risk factor for gallstone disease, more so for women than for men. It raises the risk of cholesterol gallstones by increasing biliary secretion of cholesterol, as a result of an increase in HMGCoA reductase activity. Epidemiological studies have found that the lithogenic risk of obesity is strongest in young women and that slimness protects against cholelithiasis.

In a follow up study of 90000 women, a striking monotonic increase in gallstone risk with obesity was observed. Women with a body mas index (BMI) greater than $45 \mathrm{~kg} / \mathrm{m}^{2}$ had a sevenfold excess risk as compared with those with a BMI less than $24 \mathrm{~kg} / \mathrm{m}^{2}$. The annual gallstone incidence rose parallel with the BMI, up to $2 / 100 /$ year in morbidly obese. The risk seemed greater when obesity developed early in life (obesity present by the age of 18 and subsequently maintained). ${ }^{28}$ The intentional, long term, moderate weight changes over a 16 year period progressively increased the risk of cholecystectomy in women, from light (2.3-4.1 $\mathrm{kg}$ (5-9 lb) of weight loss and gain) to moderate and to severe cyclers $(\geqslant 9.0 \mathrm{~kg}(\geqslant 20 \mathrm{lb})$ of weight loss and gain), compared with weight maintainers. ${ }^{29}$

In most studies, obesity in men as expressed by BMI, was not related to an increased gallstone formation. ${ }^{30}$ As abdominal or central obesity is associated in both men and women with hypertriglyceridaemia, low plasma high density lipoprotein (HDL) concentrations, impaired glucose tolerance, hyperinsulinaemia etc, all metabolic abnormalities linked with gallstones, one might expect an association between gallstones and abdominal obesity. A significant stepwise relationship of gallstones with waist/hip circumference ratio was found in men aged 40-69 years, ${ }^{32}$ although there was no association between BMI and 
gallstones in this population. Further studies confirmed that men's chances of having gallstones are increased by having an abdominal distribution of body fat, leading to the conclusion that obesity represents a risk for gallstones both through total body fat mass and through fat regional distribution.

RAPID WEIGHT LOSS

Weight reduction in obesity is associated with gallstone formation risk. Different studies in the morbidly obese presenting for gastric bypass surgery or after a very low calorie diet showed the occurrence of sludge and gallstones in $10 \%$ to $25 \%$ of patients in a few weeks after slimming procedures. ${ }^{33}$ During weight loss, bile lithogenicity is further enhanced by increased excretion of cholesterol due to the decrease in the synthesis and pool size of bile acids, and to the rapid mobilisation of cholesterol from adipose tissue stores. In the case of severely fat restricted diets, gallstone formation is also favored by gallbladder stasis. Enhancing gallbladder emptying by inclusion of a small amount of dietary fat inhibits gallstone formation in patients undergoing rapid weight loss. ${ }^{34}$

The effect of weight loss on bile lithogenicity is dependent on the initial body weight, on the calorie and fat content of the diet and on the rate of weight loss. A dramatically increasing risk for gallstone formation was found at rates of weight loss above $1.5 \mathrm{~kg} /$ week. $^{35}$

\section{HYPERTRIGLYCERIDAEMIA}

Most biliary stones are made of cholesterol; lipoprotein lipids are precursors of biliary lipids; synthesis, uptake, and degradation of plasma lipoproteins occur in the liver; cholesterol and bile acids in bile are the only means of eliminating cholesterol from the body. Yet, even in the largest clinical series, no definite association trends between serum lipids and gallstones have been found, except for a high frequency of gallstones in subjects with hypertriglyceridaemia (type IV hyperlipoproteinaemia). ${ }^{36}$ Nearly all patients with hypertriglyceridaemia have supersaturated gallbladder bile even if they are slim. ${ }^{36}$ Most studies found no relationship between plasma cholesterol and gallstones, but suggested that the gallstone risk varies inversely with plasma total HDL or HDL3 cholesterol, ${ }^{37}$ attributing to HDL cholesterol, a "protective" effect against gallstone formation.

DRUGS LOWERING SERUM CHOLESTEROL CONCENTRATION

All fibric acid derivatives increase biliary cholesterol saturation while lowering serum cholesterol. Clofibrate is a potent inhibitor of hepatic ACAT. ACAT inhibition leads to an increased availability of free or unesterified cholesterol for secretion into bile, favouring gallstone formation.

DIABETES MELLITUS

Although gallbladder function is impaired in the presence of diabetic neuropathy, and regulation of hyperglycaemia with insulin seems to raise the lithogenic index, association of gallstones with diabetes mellitus remains controversial. Relationships are more complex; only some diabetics are at risk.

INTESTINAL HYPOMOTILITY

Intestinal hypomotility can be a primary factor in gallstone formation, as suggested by the demonstration of an increased deoxycholate concentration in the bile of non-obese women having slow intestinal transit. ${ }^{38}$ Patients with acromegaly, treated with octreotide, develop gallbladder and intestinal hypomotility, with an increased proportion of deoxycholate in bile, as well as cholesterol supersaturation. ${ }^{39}$ Patients with diabetes and autonomic neuropathy may be at risk of forming gallstones by the same mechanism. In addition, gallbladder stasis allows sufficient time for nucleation in these patients.

\section{SPINAL CORD INJURY}

Necropsy studies first revealed an increased prevalence of gallstones in subjects with spinal cord injury. ${ }^{40}$ This was subsequently confirmed in patients with injury above the $\mathrm{T} 7$ through T10 level, the site of the emergence of the sympathetic innervation for the gallbladder. Lithogenic risk is due to gallbladder and intestinal hypomotility.

DIET

One of the main environmental exposures contributing to gallstone formation is the nutritional exposure. The progressive increase in the prevalence rate of gallstones during this century supports the role of lifestyle and dietary factors in gallstone pathogenesis. In Japan, postwar westernisation has provided an example for the interplay between environment and disease. Since the late 40 s, the prevalence of gallstones in Tokyo has more than doubled. Moreover, there has been a change from pigment to cholesterol gallstones and the sex ratio has changed in favour of females. ${ }^{41}$ This increase in gallstone incidence was associated with an increased fat intake and a decreased fibre content of the diet and consequently was attributed to the westernisation of the Japanese diet.

Studies in France have observed a higher caloric intake in subjects with gallstones than in controls. ${ }^{42}$ Refined carbohydrates cause obesity, raise plasma triglyceride and fasting plasma insulin level, and lower plasma HDL cholesterol. Most cholesterol is endogenously synthetised, so dietary cholesterol has only a limited impact on cholesterol saturation. Studies on the influence of various fats on gallstone formation offered contradictory results, most finding no association at all with animal fats and proteins with gallstone formation. For vegetable fats and protein, an inverse association with gallstones was found in some studies, but not confirmed in others.

A high fibre intake in the form of wheat bran lowers the cholesterol saturation of bile. Fibres have a protective effect against cholesterol gallstones by accelerating intestinal transit and hence decreasing the deoxycholate in bile. An 
inverse relationship was found between vegetarian diet and the risk of gallstones. ${ }^{43}$

Calcium intake seems to be inversely associated with gallstone prevalence. ${ }^{44}$ Dietary calcium decreases cholesterol saturation of gallbladder bile by preventing the reabsorption of secondary bile acids in the colon. Vitamin $C$ influences $7 \alpha$ hydroxylase activity in the bile and it was shown that ascorbic acid might reduce lithogenetic risk in adults. ${ }^{45}$ Coffee consumption seems to be inversely correlated with gallstone prevalence, due to an increased enterohepatic circulation of bile acids.

Dietary factors are significant independent exposures; nevertheless, the current evidence, deriving from a recent meta-analysis of all published studies indicates as certain only the positive association of sugars and the negative association of fibres and alcohol with cholesterol gallstones. ${ }^{46}$

Fasting in the short term increases the cholesterol saturation of gallbladder bile and, in the longer term, gallbladder stasis can lead to sludge and eventually gallstone formation. Younger women with gallstones were shown to be more prone to skip breakfast than controls. ${ }^{47}$ A shorter overnight fasting is protective against gallstones in both sexes. ${ }^{48}$

\section{ALCOHOL CONSUMPTION}

Some experimental studies have suggested the protective effect of alcohol against gallstone formation. Alcohol intake has been shown to reduce bile lithogenicity in humans. ${ }^{48-50}$ The protective effect of alcohol may occur via the liver, by increasing the conversion of cholesterol to bile acids or by altering the enterohepatic circulation of bile acids, including deoxycholic acid. Moderate alcohol consumption also raises plasma HDL cholesterol concentrations.

SMOKING

Data related to smoking as a risk factor for gallstones are inconsistent. Some authors found a linear relationship between amount smoked and gallstone risk, ${ }^{31}$ while other studies found no relation between smoking and gallstones. Smoking is associated with low plasma HDL cholesterol concentrations, a risk factor for gallstones. It also depresses prostaglandin synthesis and mucus production in the gallbladder.

SOCIOECONOMIC STATUS

Diehl et al analysed the socioeconomic status in Mexican Americans as compared with nonHispanic whites and observed that those living in affluent neighbourhoods, with high occupational status, high family incomes, and high educational attainment had lower rates of gallstones than those lower on the social scale. ${ }^{51}$ Interestingly, at high levels of socioeconomic status, the ethnic differences in gallbladder disease prevalence narrowed or even reversed. As other studies failed to find an association, the relation between socioeconomic status and gallstone disease is still controversial.
Box 4: Strategy and measures for cholesterol gallstone prevention

(1) Prevention of bile supersaturation in cholesterol

- Reduce BMI in the obese by gradual weight loss; avoid weight cycling.

- Lower serum triglyceride concentration.

- Increase hydrophylic bile acid content of bile (chenodeoxycholic acid, ursodeoxycholic acid).

- Lower hydrophobic bile acid content of bile (high fibre high calcium diet, normal intestinal transit, antibiotics, etc).

- Practice regular physical exercise.

(2) Prevention of accelerated nucleation and mucus secretion

- Take anti-inflammatory non-steroidal: aspirin (?)

(3) Prevention of gallbladder stasis

- Keep a regular eating pattern, avoid long periods between meals.

- Eat small fatty meals (or administer cholecystokinin) during rapid weight loss.

(4) Prevention of intestinal hypomotility

- Stimulate intestinal transit (high fibre high calcium diet, cisapride).

- Lower intestinal pH (lactulose).

\section{PHYSICAL ACTIVITY}

The potential role of physical activity in preventing cholesterol gallstone formation is largely unknown. Regular exercise, in addition to facilitating weight control, alone or in combination with dieting, improves several metabolic abnormalities related to both obesity and cholesterol gallstones. In a prospective study in 60290 women, increased physical activity was associated with a significant reduction in the risk of cholecystectomy. Not only vigorous physical activity, but also moderate forms of exercise, such as brisk walking, were associated with a reduced risk of cholecystectomy. In contrast, sedentary behaviour, as assessed by time spent sitting, was positively associated with the risk of cholecystectomy. ${ }^{52}$

\section{Cholesterol gallstone prevention}

Gallstones are highly prevalent in most Western countries. Although symptomatic and complicated stones represent less than $20 \%$ of all gallstones, they lead to important morbidity and complications, and to high costs of medical care, making gallstone prevention highly desirable. Based on the present epidemiological knowledge, we are now in the position to do something about cholesterol gallstone prevention.

Primary prevention would be the inhibition of formation of stones in subjects who have not previously had gallstones. It could address the entire population with recommendations for a healthy lifestyle, but could be most productively focused on subjects at increased risk, that is obese women, with many pregnancies and positive family history, etc. The strategy for 
preventing cholesterol gallstone formation should be targeted to the main pathogenetic mechanisms: supersaturation of bile in cholesterol; accelerated nucleation; impaired gallbladder emptying and intestinal hypomotility (box 4).

First and foremost, cholesterol supersaturation is a matter of obesity, hence it should be approached by reducing BMI in obese people and by lowering triglyceride serum concentrations. Rapid weight loss in the obese should be replaced by a gradual weight loss sustained over a long period. The long term numerous weight cycles should be avoided as each weight reduction regimen causes tissue cholesterol from the shrinking adipose tissue to be excreted in bile. Increased cholesterol saturation in the bile could be prevented by increasing the bile proportion of hydrophilic bile acids. Administration of chenodeoxycholic or ursodeoxycholic acids would be too expensive an approach to be recommended, except for small risk groups (that is, morbidly obese women during rapid weight loss). Reduction of the proportion of hydrophobic bile acids, that is deoxycholic acid, could be reached by stimulating intestinal motility and by a high calcium high fibre diet in constipation cases. Antibiotics would diminish the number of bile acid metabolising anaerobes.

Accelerated nucleation and mucus secretion in the gallbladder might be diminished by prostaglandin inhibitors. Aspirin, in the dose of four tablets a day, was shown to prevent gallstone formation in rapid weight reduction patients. But it was not confirmed that persons regularly taking aspirin have a lower incidence of gallstones, making it questionable whether "one aspirin a day keeps the gallstone away". ${ }^{53}$

Gallbladder stasis should be approached by a regular eating pattern, avoiding long periods between meals, by a bedtime snack to reduce overnight fasting or by small fatty meals during rapid weight loss.

Stimulation of intestinal motility would decrease bacterial bile acid metabolisation. Intestinal $\mathrm{pH}$ lowering might also lead to deoxycholate reduction in bile. A high calcium high fibre diet, as well as lactulose or prokinetics (cisapride) could thus prevent cholesterol gallstone formation in constipation.

Descriptive epidemiology suggests consistently that environmental factors characterising modern Western civilisation and urbanisation may be responsible for most cholesterol rich gallstones. All these factors are amenable to prevention. Habits (smoking, coffee, and alcohol consumption) and activities (physical load) can be changed, diets modified, and thus exposures limited. ${ }^{54}$ People (particularly women) should limit their energy intake and especially readily absorbed carbohydrates and animal fats so as to maintain the ideal body weight. In addition, they should eat enough dietary fibre to avoid constipation, they should respect a regular eating pattern, and avoid a long overnight fasting. Of course, no one would ever suggest restricting the family size by modulating the number of pregnancies! A modest alcohol intake could be protective, but should not be recommended to non-drinkers. Cessation of smoking is advisable, as well as a sustained physical activity, even if limited to a 30 minute brisk walk daily for five days a week. In fact, the preventive measures for cholesterol gallstone formation reproduce those already recommended for cardiovascular disease prevention and they should be proposed at least in high risk individuals.

\section{Questions (answers on p 229)}

1. Name the populations with the highest prevalence of cholesterol gallstones.

2. Name the populations with the lowest prevalence of cholesterol gallstones.

3. Name the facts which support the intervention of the genetic control in cholesterol gallstone formation.

4. The contributive factors to cholesterol gallstone formation in obese women are:

(A) Age of obesity onset.

(B) Severity/degree of obesity.

(C) Distribution of body fat.

(D) Serum cholesterol concentration.

(E) Degree of weight cycling.

5. The current evidence supports the protective role of the following dietary components in cholesterol gallstone formation:

(A) Refined carbohydrates.

(B) Fibres.

(C) Alcohol.

(D) Animal proteins

(E) Vitamin C.

6. Bile supersaturation in cholesterol might be prevented by:

(A) Regular physical exercise.

(B) Regular aspirin intake.

(C) Avoidance of severe weight cycling.

(D) Lactulose.

(E) Ursodeoxycholic acid.

1 Bateson MC. Gallbladder disease prevalence and cholecystectomy rates. In: Capocaccia L, Ricci G, Angelico F, et al, eds. Recent advances in the epidemiology and prevention of galleds. Recent advances in the epidemiology and prevention of gallstone dised

2 Bates T, Harrison M, Lowe D, et al. Longitudinal study of gall stone prevalence at necropsy. Gut 1992;33:103-7.

3 Acalovschi M, Dumitrascu D, Caluser I, et al. Comparative Acalovschi M, Dumitrascu D, Caluser I, et al. Comparative
prevalence of gallstone disease at 100-year interval in a large Romanian town, a necropsy study. Dig Dis Sci 1987;32:3547

4 Barbara L, Sama C, Morselli Labate AM, et al. A population study on the prevalence of gallstone disease: the Sirmione study. Hepatology 1987; 7:913-7.

5 Angelico F, Del-Ben M, Barbato A, et al. Ten-year incidence and natural history of gallstone-disease in a rural population of women in central Italy. The Rome Group for the Epidemiology and prevention of Cholelithiasis (GREPCO). Ital $\mathcal{F}$ Gastroenterol 1997;29:249-54.

6 Jorgensen T, Hougaard JT. Eleven-year cumulated incidence of gallstone formation in an unselected Danish population. Gastroenterology 1996;110(suppl 4):A21.

7 Sampliner RE, Bennett PH, Comess LJ, et al. Gallbladder

Sampliner RE, Bennett PH, Comess LJ, et al. Gallbladder
disease in Pima Indians. Demonstration of high prevalence disease in Pima Indians. Demonstration of high prevalence and early onset

8 Everhart JE, Khare M, Hill M, et al. Prevalence and ethnic differences in gallbladder disease in the United States. Gastroenterology 1999;117:632-9.

9 Covarrubias C, Valdivieso V, Nervi F. Epidemiology of gallstone disease in Chile. In: Capocaccia L, Ricci G, Angelico $\mathrm{F}$, et al, eds. Epidemiology and prevention of gallstone disease. Lancaster: MTP Inc, 1984: 26-30.

10 Everhart JE. Gallstones. In: Everhart JE, ed. Digestive diseases in the United States: epidemiology and impact. (NIH Publication No 94-1447.) 1994: 647-90.

11 Scragg RKR, McMichael AJ, Seamark RF. Oral contraceptives, pregnancy, and endogenous ostrogen in gallstone tives, pregnancy, and endogenous ostrogen in gall

12 Valdivieso V, Covarrubias C, Siegel F, et al. Pregnancy and cholelithiasis: pathogenesis and natural course of gallstones diagnosed in early puerperium. Hepatology 1993;17:1-4. 
13 Royal College of General Practitioners' Oral Contraceptive Study Oral contraceptives and gallbladder disease. Lancet 1982;ii: $957-60$

14 VanErpecum KJ, Vanberge Henegouwen GP, Verschoor I, et al. Different hepatobiliary effects of oral and transdermal estradiol in postmenopausal women. Gastroenterology 1991; 100:482-8.

15 Waldhausen JHT, Benjamin DR. Cholecystectomy is becoming an increasingly common operation in children. Am F Surg 1999;177:364-7.

16 Bertolotti M, Bertolotti S, Menozzi D, et al. Ageing and bile acid metabolism: studies on $7 \alpha$ hydroxylation of cholesterol in humans. In: Paudies in humans. In: Paumgartner G, Gerok W, eds. Trends in bile acid resea.

17 Einarsson K, Nilsell K, Leijd B, et al. Influence of age on secretion of cholesterol and synthesis of bile acids in the liver. N Engl F Med 1985;313:277-82.

18 Diehl AK. Genetic, ethnic and environmental factors: findings from the San Antonio heart study. In: Capocaccia L Ricci G, Angelico F, et al, eds. Recent advances in the epidemi ology and prevention of gallstone disease. Dordrecht: Kluwer Academic Publishers, 1991: 89-94.

19 Miquel JF, Covarrubias C, Villaroel L, et al. Genetic epidemiology of cholesterol cholelithiasis among Chilean Hispanics, Amerindians and Maoris. Gastroenterology 1998;115: 1Cs, Amerin

20 Walker ARP, Segal I, Posner R, et al. Prevalence of gallstones in elderly black women in Soweto, Johannesburg, as assessed by ultrasound. Am $\mathcal{F}$ Gastroenterol 1989;84:1383-5.

21 Gilat T, Feldman C, Halpern Z, et al. An increased familial frequency of gallstones. Gastroenterology 1983;84:242-6.

22 Sarin SK, Negi VS, Dewan R, et al. High familial prevalence of gallstones in first-degree relatives of gallstone patients. Hepatology 1995;22:138-41.

23 Van der Linden W, Simonson N. Familial occurrence of gallstone disease. Incidence in parents of young patients. Human Hered 1973;23:123-7.

24 Danzinger RG, Gordon H, Schoenfield LJ, et al. Lithogenic bile in siblings of young women with cholelithiasis. Mayo Clin Proc 1972;47:762-6.

25 Kesaniemi YA, Koskenvuo M, Vuoristo M, et al. Biliary lipid composition in monozygotic and dizygotic pairs of twins. Gut 1989;30:1750-6.

26 Khanuja B, Cheah Y-C, Nishina PM, et al. Lith1, a major gene affecting cholesterol gallstone formation among inbred strains of mice. Proc Natl Acad Sci U S A 1995;92:7729-34.

27 Juvonen T, Kervinen K, Kairaluoma MI, et al. Gallstone cholesterol content is related to apolipoprotein $\mathrm{E} 4$ polymorphism. Gastroenterology 1993;104:1806-11.

28 Maclure KM, Hayes KC, Colditz GA, et al. Weight, diet and the risk of symptomatic gallstones in middle-aged women. $N$ Engl F Med 1989;321:563-9.

29 Syngal S, Coakley EH, Willett WC, et al. Long-term weight patterns and risk for cholecystectomy in women. Ann Intern Med 1999;130:471-7.

30 Kono S, Shinchi K, Todoroki I, et al. Gallstone disease among Japanese men in relation to obesity, glucose intolerance, exercise, alcohol use and smoking. Scand f Gastroenterol 1995;30:372-6.

31 Sahi T, Paffenbarger RSJr, Hsieh C, et al. Body mass index, cigarette smoking and other characteristics as predictors of self-reported, physician-diagnosed gallbladder disease in male college alumni. Am f Epidemiol 1998;147:644-51.

32 Heaton KW, Braddon FEM, Emmett PM, et al. Why do men get gallstones? Roles of abdominal fat and hyperinsulimen get gallstones? Roles of abdominal fat and hyp

33 Yang H, Petersen GM, Roth MP, et al. Risk factors for gallstone formation during rapid loss of weight. Dig Dis Sci 1992;37:912-8.

34 Gebhard RI, Prigge WE, Ansel HJ, et al. The role of gallbladder emptying in gallstone formation during dietinduced rapid weight loss. Hepatology 1996;24:544-8.

35 Weinsier RL, Wilson LJ, Lee J. Medically safe rate of weight loss for the treatment of obesity: a guideline based on risk of gallstone formation. Am F Med 1995;98:115-7.

36 Ahlberg J. Serum lipid levels and hyperlipoprotinaemia in gallstone patients. Acta Chir Scand 1979;145:373-7.

37 Petitti D, Friedman GD, Klatsky AL. Association of a history of gallbladder disease with a reduced concentration of high-density-lipoprotein cholesterol. N Engl f Med 1981; 304:1396-8.

38 Heaton KW, Emmett PM, Symes CL, et al. An explanation for gallstones in normal-weight women: slow intestinal tranfor gallstones in normal-weigh
sit. Lancet 1993;341:8-10.

39 Hussaini SH, Pereira SP, Veysey MJ, et al. Roles of gallbladder emptying and intestinal transit in the pathogenesis of
octreotide induced gallbladder stones. Gut 1996;38:775-83.

40 Apstein MD, Dalecki-Chipperfield K. Spinal cord injury is a risk factor for gallstone disease. Gastroenterology 1987;92: 966-8

41 Kameda H, Ishihara F, Shibata K, et al. Clinical and nutritional study on gallstone disease in Japan. Fapanese Medical fournal 1984;23:109-13.

42 Sarles H, Chabert C, Courcoul MA. Dietary evolution in gallstone patients from 1957 to 1972. Real frequency of gallstone disease. Biological Gastroenterology 1973;6:162-3.

43 Pixley F, Wilson D, McPherson K, et al. Effect of vegetarianism on development of gallstones in women. $B M \mathcal{F}$ 1985;291:11-12.

44 Moerman CJ, Smeets FW, Kromhout D. Dietary risk factors for clinically diagnosed gallstones in middle-aged men.
25-year follow-up study. Ann Epidemiol 1994;4:248-54.
45 Simon JA, Hudes ES. Serum ascorbic acid and other correlates of gallbladder disease among US adults. Am $\mathcal{F}$ Public Health 1998;88:1208-12.

46 Tseng $M$. Dietary intake and gallbladder disease: a review. Public Health Nutrition 1999;2:161-72.

47 Capron JP, Delamarre J, Herve MA, et al. Meal frequency and duration of overnight fast: a role in gallstone formation? $B M \mathcal{F}$ 1981;283:1435

48 Attili AF, Scafato E, Marchioli R, et al, MICOL group. Diet and gallstones in Italy: the cross-sectional MICOL results. Hepatology 1998;27:1492-8.

49 Scragg RKR, McMichael AJ, Baghurst PA. Diet, alcohol and relative weight in gallstone disease: a case-control study. BMF 1984;288:1113-9.

50 Friedman GD, Kannel WB, Dawber TR. The epidemiology of gallbladder disease: observations in the Framingham study. F Chronic Dis 1966;19:273-92.

51 Diehl AK, Rosenthal M, Hazuda HP, et al. Socioeconomic status and the prevalence of clinical gallbladder disease. 7 Chronic Dis 1985;38:1019-26.

52 Leitzmann MF, Rimm EB, Willett WC, et al. Recreational physical activity and the risk of cholecystectomy in women. N Engl f Med 1999;341:777-84.

53 Pazzi P, Scagliarini R, Sighinolfi D, et al. Nonsteroidal antiinflammatory drug use and gallstone disease prevalence: case control study. Am f Gastroenterol 1998;93:1420-4.

54 Hofmann AF. Primary and secondary prevention of gallstone disease: implications for patient management and research priorities. Am F Surg 1993;165:541-8.

\section{References for table 1}

Marinovic I, Guerra C, Larach G. Incidencia de litiasis biliar en material de autopsias y analisis de composicion de los calculos. Revista Med Chil 1972;100:1320-7.

Balzer K, Goebell H, Breuer N, et al. Epidemiology of gallstones in a German industrial town (Essen) from 19401975. Digestion 1986;33:189-97.

Zahor Z, Sternby NH, Kagan A, et al. Frequency of cholelithiasis in Prague and Malmö. An autopsy study. Scand $\mathcal{F}$ Gastroenterol 1974;9:3-7.

Lindström GG. Frequency of gallstone disease in a welldefined Swedish population. Scand F Gastroenterol 1977;12: 341-6

Bateson $M$, Bouchier IAD. Prevalence of gallstones in Dundee: a necropsy study. BMF 1975;iv:427-9.

Barker DJP, Gardner MJ, Power C, et al. Prevalence of gallstones at necropsy in nine British towns: a collaborative study. BMF 1979;ii: 1389-92.

Mendez-Sanchez N, Jessunen J, Ponciano-Rodriguez G, et al. Prevalence of gallstones in Mexico. A necropsy study. Dig Dis Sci 1993;38:680-3.

Domellöf L, Lowenfels AB, Sipponen P. Prevalence of gallstones in Finland. An autopsy study in the Helsinki area. Scand 7 Gastroenterol 1984;19:761-4.

Douss TW, Castleden WM. Gallstones and carcinoma of the large bowel. N Z Med f 1973;77:162-5.

Lieber MM. The incidence of gallstones and their correlation with other diseases. Ann Surg 1952;135:394-405.

Cleland JB. Gallstones in seven-thousand post-mortem examinations. Med F Aust 1953;ii:488-90.

Newman HF, Northup JD. The autopsy incidence of gallstones. Int Abst Surg 1959;109:1-13.

Hogan J, Lonergan M, Holland PDJ. The incidence of cholelithiasis in an autopsy series. F Ir Med Assoc 1977;70:608-11.

Torvik A, Hoivik B. Gallstones in an autopsy series. Incidence, complications and correlations with carcinoma of the complications and correlations with carcin

Acalovschi M, Dumitrascu D, Caluser I, Ban A. Comparative prevalence of gallstone disease at 100-year interval in a large
Romanian town: a necropsy study. Dig Dis Sci 1987;32:3547.

Kalos A, Delidou A, Kordosis T, et al. The incidence of gallstones in Greece: an autopsy study. Acta HepatoGastroenterology 1977;24:20-3.

Swang WS. Cholelithiasis in Singapore. A necropsy study. Gut 1970;11:141-8.

Stitnimankarn T. The necropsy incidence of gallstones in Thailand. Am f Med Sci 1960;240:349-52.

\section{References for table 2}

Barbara L, Sama C, Labate AMM, et al. A population study on the prevalence of gallstone disease. The Sirmione study. Hepatology 1987;7:913-7.

Jörgensen T. Prevalence of gallstones in a Danish population. Am f Epidemiol 1987;126:912-21.

Glambek I, Kvaale G, Arnesjo B, et al. Prevalence of gallstones in a Norwegian population. Scand $\mathcal{F}$ Gastroenterol 1987;22:

Berndt H, Nürnberg D, Pannwitz H. Prävalenz der Cholelithiasis. Ergebnisse einer epidemiologischen Studie mittels Sonographie in der DDR. Z Gastroenterol 1989;27:662-6.

Sporea A, Goldis A, Mateoc A. Echographic screening concerning the incidence of gallstones in a general population. Gastroenterology 1993;104:A379.

Loria P, Dilengite MA, Bozzoli M, et al. Prevalence rates of gallstone disease-the Chianciano population study. Eur $\mathcal{F}$ Epidemiol 1994;10:143-50.

Misciagna G, Leoni C, Elba S, et al. The epidemiology of cholelithiasis in southern Italy. Eur f Gastroenterol Hepatol 1994;6:937-41.

Muhrbeck O, Ahlberg J. Prevalence of gallstone disease in a Swedish population. Scand $\mathcal{F}$ Gastroenterol 1995;30:1125-8. 
Attili AF, Carulli N, Roda E, et al. Epidemiology of gallstone disease in Italy: prevalence data of the Multicenter Italian
Study on Cholelithiasis (MICOL). Am $\mathcal{f}$ Epidemiol 1995; 141:158-65.

Heaton KW, Braddon FEM, Mountford RA, et al. Symptomatic and silent gallstones in the community. Gut 1991;32: 316-20.

Tomecki R, Dzieniszewski J, Gerke W, et al. Cholecystolithisis in the urban population of Poland. Polskie Arch Med Wewnetrznej 1995;94:243-9.

Okolicsany L, Passera D, Nassuato G, et al. Epidemiology of gallstones in an older Italian population in Montegrotto Terme, Padua. 7 Am Geriatr Soc 1995;43:902-5.

Caroli-Bosc FX, Hastler P, Delabre B, et al. Prevalence and risk factors of gallstone disease in a town of South of France. Gastroenterology 1996;110:A9.

Martinez de Pancorbo C, Carballo F, Horcajo P, et al. Prevalence and associated factors for gallstone disease: Prevalence and associated factors for gallstone disease:
results of a population survey in Spain. $\mathcal{F}$ Clin Epidemiol results of a populati
1997;50:1347-55.

Kratzer W, Kachele V, Mason RA, et al. Gallstone prevalence in Germany: the Ulm Gallbladder Stone Study. Dig Dis Sci 1998;43:1285-91.

Nomura H, Kashiwagi S, Hayashi J, et al. Prevalence of gallstone disease in a general population of Okinawa, Japan. Am F Epidemiol 1988;128:598-605.

Khuroo MS, Mahajan R, Zarger SA, et al. Prevalence of biliary tract disease in India: a sonographic study in an adult population in Kashmir. Gut 1989;30:201-5.

Lu SN, Chang WY, Wang LY. Risk factors for gallstones among Chinese in Taiwan. F Clin Gastroenterol 1990;12:543-

Zhao Y, Zhang R, Hu Y, et al. An epidemiological survey of gallstones with gray-scale ultrasound. $f$ West China Univ Med Sci 1990;21:217.

Prathnadi P, Miki M, Supraset S. Incidence of cholelithiasis in the northern part of Thailand. $\mathcal{F}$ Med Assoc Thai the northern par

Chen CY, Lu CL, Huang YS, et al. Age is one of the risk factors in developing gallstone disease in Taiwan. Age Ageing tors in developin

Maurer KR, Everhart JE, Knowler WC, et al. Risk factors for gallstone disease in the Hispanic populations of the United States. Am F Epidemiol 1990;131:836-4

Hanis GL, Hewett-Emmett D, Kubrulsky LF, et al. An ultrasound survey of gallbladder disease among Mexican
Americans in Starr County, Texas: frequencies and risk factors. Ethnicity Dis 1993;3:32-43.

Everhart JE, Khare M, Hill M, et al. Prevalence and ethnic differences in gallbladder disease in the United States. Gastroenterology 1999;117:632-9.

Covarrubias C, Miquel J, Puglielli L, et al. The role of ethnicity and other risk factors for cholelithiasis in a highly prevalent area: cross-sectional and cohort studies in Chilean and Amerindian Araucanos. Gastroenterology 1995;108:A1053.

Moro PL, Checkley W, Gilman RH, et al. Gallstone disease in Peruvian coastal natives and highland migrants. Gut 2000;46:569-73.

Bagi Abdel M, Arabi M, Abdel Rahim B, et al. Prevalence of gallbladder disease in Sudan: first sonographic field study in adult population. Gastroenterology 1991;100:A307.

\section{Answers}

1. Pima Indians in Arizona, other Indian tribes in North America, Mapuche Indians, and Chilean Mestizos in Chile.

2. African and Asian populations.

3. The facts are:

- Racial/ethnic differences in gallstone prevalence.

- Family clustering of gallstone carriers.

- Higher prevalence in monozygotic $v$ dizygotic twins.

- Lith1 and Lith2 genes in mice strains susceptible to form gallstones.

- ApoE4 genotype in humans associated with increased gallstone formation.

4. (A), (B), (E).

5. (B), (C), (E).

6. (A), (C), (E). 